\title{
JUNTAR ERARIOS \\ Y MONTES DE PIEDAD: UN ARBITRIO \\ BARROCO ANTE LAS CORTES DE CASTILLA *
}

\author{
PEDRO SCHWARTZ \\ Catedrático de Historia de las Doctrinas Económicas \\ de la Universidad Autónoma de Madrid
}

\begin{abstract}
RESUMEN
Las dificultades financieras de la Corona española en el Siglo de Oro favorecieron la propuesta de emparejar los ya conocidos montes de piedad con unos nuevos cerarios püblicoss, que facilitarian fondos a la Corona y a los particulares sin caer en la práctica nefanda de la usura, contratando a censo y no a préstamo. Las Cortes de Castilla comenzaron apadrinando el proyecto, pero lo hundieron para evitar que el Conde Duque de Olivares lo convirtiese en un instrumento de recaudación coactiva de la Hacienda.

Queda patente que las Cortes de Castilla mantenían sus poderes de resistencia un siglo después de la derrota de Villalar. Por eso, los memoriales de los arbitristas no eran dirigidos sólo al Rey y sus ministros, sino también a las Cortes, que reflejaban una opinión pública muy viva y sensible. El análisis del contrato de censo, con el que se evitaba la condena teológica de la usura, ayuda a trazar la lenta penetración del espiritu capitalista en la España barroca.
\end{abstract}

* Texto revisado de una conferencia impartida en el Il Seminario sobre Instituciones en la España moderna, el 30 de noviembre de 1993. Agradezco la ayuda inestimable de mi asistente de investigación Elena Gallego. También me han servido para corregir errores de cálculo en el valor del contenido de oro de los ducados las criticas de J. Alcala-Zamora. En el debate que siguio a mi ponencia, en el que oi atinadas reflexiones de Francisco Burgos, quedó claro que la re. sistencia de las Cortes y las ciudades no debia interpretarse necesariamente como una victoria "democrática», sino a menudo como la reafirmacion de intereses oligárquicos. Los evaluadores de la Revista de Historia Económica también han hecho útiles sugerencias. Por fin agradezco la colaboración de los bibilotecarios del Archivo General de Simancas, de la Academia de la Historia y de la Biblioteca del Senado. La ortografia de las citas es la de las fuentes consultadas, que a veces modernizan la escritura en sus reediciones actuales de textos del xvi o xvit. No reproduzco sin embargo la $\mathbf{s}$ alta de los impresos o manuscritos de la época, ni las tildes que sustituyen la $\mathbf{n}$, la m, o la ue en equew.

Rrvisto de Historia Fommimicu

Ario XIV, Invicrmo 19\%, N.1 


\section{ABSTRACT}

Given the financial difficulties of the Spanish Crown in the 17th century, a willing ear was turned to proposals for combining Italian type Monti di Pietà with Crown chartered erarios, to finance both the Crown and private borrowers: nefarious usury was avoided by granting loans under the guise of a mortgage or lien. The Cortes of Castille favoured the project, but later scuppered it to stop the Count Duke of Olivares from using it as a taxing device.

The study makes it clear that the Cortes kept their powers of resistance for a century after the rout of the Comuneros at Villalar: hence the abundance of projects ad. dressed to the Cortes and a lively and sensitive public opinion, beside those addressed to the King and his ministers. The analysis of loans granted under mortgages and liens helps map the slow progress of the spirit of capitalism in baroque Spain.

El arbitrio de reunir erarios y montes de piedad en una sola institución, como modo de reducir tanto los impuestos como las usuras, fue un bajel diseñado en tiempos de Felipe II y botado en las Cortes del reinado de Felipe III. No llegó a navegar, pues el Conde de Olivares intentó requisarlo para, con ayuda de su Junta de Reformación, transformarlo en una fuente de crédito público, creando asi un banco del Estado o un «banco nacional» (cual iba a calificarlo Campomanes en 1777) ', visto lo cual las Cortes de Castilla lo vararon definitivamente. En este trabajo reinterpreto la historia del fracaso de esta idea de unir erarios con montes de piedad en el Antiguo Régimen, y para ello utilizo un doble punto de vista: el de la historia de las instituciones en el siglo XvIl, y el de la teoría económica actual.

En efecto, por un lado, quiero preguntar el porqué del fracaso del arbitrio de los erarios, pese a un apoyo politico y doctrinal muy extendido; averiguar en qué medida el apoyo oficial a los erarios ayudó a transformar la condena de la usura en la aceptación del interés; comprender cómo fue naciendo el proyecto de un banco nacional, que acabaría concretándose en la gran picardia del Banco de San Carlos; descubrir si los memorialistas sólo escribian para el Rey, o también para las Cortes y la opinión pública; contribuir a la definición de los estrechos límites del poder de la mal llamada Monarquia absoluta.

Mas, por otro lado, resultaría dificil entender toda la trascendencia de las doctrinas sobre la usura y el interés del siglo xvil sin interpretarlas desde el punto de vista de la teoria del dinero de hoy dia. Tampoco sería posible pro. fundizar en la propuesta de una red de erarios públicos sin la ayuda de la teo-

1 Pedro Rodriguez de Campomanes: Apendice a la educacion popular. Parte quarta, que contiene los ocho discursos de Francisco Martinez de Mata... Madrid, Antonio Sancha, 1777. Las notas de Campomanes al texto de Martinez de la Mata vienen convenientemente reproducidas en los Memoriales y Discursos de Francisco Martinez de la Mata, edicion de (jonzalo Anes (Madrid, 1971). 
ría de los bancos centrales y de las razones y sinrazones de su nacionalización por los Estados actuales. Igual que no es posible lamentar la abusiva utilización de las sanguijuelas para curar a los enfermos del seiscientos si no se juzga esa práctica a partir de los conocimientos médicos de hoy, tampoco es posible valorar la empecinada resistencia social frente a la propuesta de creación de una red de bancos públicos o de un banco central al servicio del Estado, o comprender la paulatina aceptación del interés como un cargo lícito y no usurario, sin saber algo de la teoría económica actual.

Empleo pues en este trabajo un doble método; el de la reconstrucción bistórica de la batalla política y doctrinal en torno a los erarios, y, más generalmente, de la relación entre las propuestas de los arbitristas y las instituciones de la monarquia barroca; y lo complemento con el método de la reconstrucción teórica de las ideas económicas del seiscientos sobre usura y crédito, pues la teoría económica señala que lo inviable muere y que el mercado en fin de cuentas se impone sobre los deseos de los políticos?

\section{APARECE EL ARBITRIO DE LOS ERARIOS}

Aunque los montes de piedad eran de origen italiano y medieval, y habian sido aprobados por el V Concilio de Letrán en $1515^{3}$, la idea de acoplar los montes con erarios públicos y transformarlos asi en bancos de la Corona nació en mentes flamencas y en el último cuarto del siglo XvI.

\section{Propuesta enviada a Felipe II}

La atención de la Corona fue atraida hacia el arbitrio de juntar erarios con montes de piedad por una carta de Petrus ab Oudegherste y Petrus van Rottis

2 Mark Blaug (1992). En ese trabajo, Blaug sustituyo sus antiguos conceptos de cabsolutismow y arelativismo», que presentara en Blaug (1962) para la interpretación del pensamiento de los autores del pasado, por expresiones que hacen hincapie en que toda interpretación de ideas en la historia es una reconstruccion, sea esa reconstrucción la hecha desde el punto de vista del contenido de veracidad del pensamiento antiguo (areconstrucción racional»), sea desde -l punto de vista del significado de la vivencia histórica (areconstrucción historica»l. Sin embargo, por sugerencia del Dr. Manuel Santos, considero mas apropiado o intuitivamente claro hablar de "reconstruccion teórica" en vez de "reconstrucción racional», aludiendo asi al hecho de que los historiadores del pensamiento económico debemos tener en cuenta las teorias actuales al evaluar el contenido de veracidad de los escritos del pasado.

- El Papa León X, al culminar el dicho V Concilio de Letrán, publico la bula Inter multipleces, por la que se permitian los Montes de Piedad, mientras no cobrasen interés, sino sólo una in- 
a Felipe II. Como bien dice don Felipe Ruiz Martin, estaba fechada en Viena en 8 de agosto de 1576, al poco tiempo del decreto por el que el Rey suspendia el servicio de la deuda reconocida por su padre a los banqueros genoveses en los asientos de los libros de cuentas del Tesoro. La carta resumia un de. tallado plan de creación de una red de bancos de depósito o erarios para sustituir a los genoveses, plan que aquellos personajes habian entregado al embajador de España en Viena, y por el que el Rey podría obtener financiación abundante, asi como atender por lo menos al servicio de los juros, o deuda pública en manos de los particulares ${ }^{4}$.

Oudegherste volvió a su patria, donde el Consejo de Flandes fue encargado de estudiar el proyecto, sin resultado práctico inmediato para la puesta en práctica de su idea. Alli conoció a Luis Valle de la Cerda (quien relató todo esto en su prólogo «á los Reynos y Vasallos» de su libro sobre los erarios). Desanimado Oudegherste, pidió a Valle, a la sazón al servicio del Duque de Parma, que presentara el arbitrio en España. Vuelto a su patria, Valle tuvo noticia en 1591 de la muerte de su instructor y decidió preparar un memorial al Rey para explicar su idea 5 .

\section{Propuestas de creación de erarios bajo Felipe III}

Muerto Felipe II estando las Cortes de Castilla en sesión, se inauguró el nuevo reino con una dramática comunicación del Rey don Felipe III, en la que describia el lamentable estado de sus finanzas. Tal es la ocasión de que renaciera el interés por el arbitrio de los erarios.

El procurador Luis de Aragón dio cuenta en la sesión de 25 de noviembre de 1599 de cómo

[450] llevó un discurso que de esta materia ha escrito Luis Valle de la Cerda, Contador de la Santa Cruzada á la Junta en que por comission del Reyno ha asistido con Pedro Miranda, Hernando de Quiñones y D. Lope Ceron, con quien lo comunicó, y todos lo leyeron y consideraron el dicho discurso y otros papeles de esta materia desde el principio hasta el fin, y quedaron con la satis. faccion de este medio que el tiene, la cual no solo han tomado de los dichos pa-

\footnotetext{
demnidad moderada ad solas ministmrum impensas et aliarum rerum ad illorum conservationem. Ci. Jose Barrientos Garcia (1985), p. 189, nota 197.

4 Felipe Ruiz Martín (1969). El tema vuelve a tomarlo el Dr. Ruiz Martin en (1970. Más particularmente sobre el flamenco originador de la idea, puede leerse el articulo de Josefa Diaz de Diaz-Fernandez y Fabian Estapé (1956).

'Actas de las Cortes de Castilla, Tomo 18, Cortes de Madrid de 1598, p. 450, nota 1.
} 
peles, pero de muy grave ministros de su Magestad, a quien el Rey Don Felipe II, nuestro señor,[451] que está en el cielo, cometió el examen de este medio.

Menudearon las reuniones para estudiar la propuesta de Valle y el 9 de diciembre de 1599, Pedro de Miranda propuso se imprimieran cien ejemplares del susodicho discurso y se enviaran a las villas y ciudades con representación en Cortes. $Y$ en efecto al dia siguiente se acordó la impresión de «doscientos cuerpos» del libro. Por fin, se libraron ochenta ducados para imprimir cien ejemplares.

El titulo de la primera edición del libro de Luis Valle de la Cerda es el siguiente:

DESEMPENO / DEL PATRIMONIO DE / Su Magestad Y de los Reynos, sin daño del Rey / y vasallos, y con descanso y / alivio de todos. / POR MEDIO DE LOS ERARIOS / públicos y Montes de Piedad / POR LUYS VALLE DE LACERDA / Del Consejo, y Contador de su Magestad / de la Santa Cruzada EN MADRID / En casa de Pedro Madrigal, / Año MDC.

El colofón menciona quién lo sufragó:

Imprimiose es- / te libro á costa y por orden / del Reyno, en las Cortes que, / se congregaron en Madrid / el pasado año de / 1599. En Madrid / En casa de Pedro Madrigal, / Año de $M D C$.

El memorial de Valle produjo algún efecto incluso antes de ser impreso. El 14 de diciembre de 1599, el Conde de Miranda pronunció un largo discurso sobre el estado de la Hacienda y sus remedios. En él pidió que se crearan erarios en las 18 ciudades con voto en Cortes, más Lisboa, Flandes y Nápoles. Muy significativo fue su caveat de que el Rey no pudiera valerse de los erarios «sin consentimiento del Reyno junto en Cortes». Luego venia la propuesta de un estanco:

que se quiten todos los Bancos o cambios públicos y secretos ó casas de depósito, poniendo graves penas á los que de nuevo las pusieren, de manera que con esto sea fuerza acudir todos a los dichos Erarios. (530).

Esta propuesta de monopolio era de la cosecha del Conde, pues en el libro de Valle no habia ningún atisbo de forzar depósitos, a no ser el de la colocación temporal en los erarios de depósitos judiciales, rentas vacantes y otros fondos de por sí sujetos a depósito. Miranda proponía como financiación inicial nada menos que un millón de ducados (cuyo contenido de 
oro, para darnos una idea muy imperfecta y aproximada del valor de esta suma, valdria hoy unos 6.000 millones de pesetas) ${ }^{6}$ que podian tomarse, dijo, «del primer oro y plata que viene de las Indias», pero de la parte de ese tesoro que tocaba al Rey. El Rey no hizo caso.

El Reyno junto en Cortes aprobó el arbitrio de los erarios el 5 de febrero del año de 1600 y nombró seis comisarios para su fundación. El 8 de febrero enviaron las Cortes un «Memorial para Su Magestad sobre la fundacion de los Erarios, aprobada por el Reinom. Esas mismas Cortes constataron el 11 de febrero que no habia habido contestación de Su Majestad. Tampoco la hubo más tarde. Valle de la Cerda murió en 1607, «cansado y viejo» nos dice Ruiz Martín.

Quiero subrayar en este punto que, lejos de oponer las Cortes resistencia a los erarios, intentaron conseguir que la Corona los crease, es cierto que con los fondos de ésta. Era para los procuradores buena esa idea de establecer una red de erarios, es decir, lo que los ilustrados de finales del siglo Xvin llamarian un «banco nacional», mientras la Corona sufragara el capital y pudiesen las Cortes limitar el uso de sus fondos por el Rey: en especial porque creian ese capital público, bien controlado por los poderes municipales, incitaria al depósito de fondos privados en esos erarios, convirtiéndolos de hecho en montes de piedad financiadores de la economía privada.

Diecisiete años después, las Cortes seguian sin cejar en su empeño de mover a D. Felipe III y su valido el Duque de Lerma a crear una red de erarios y montes de piedad. En efecto, «a nueve días del mes de Hebrero del año de 1617» estando el Reino junto en Cortes «en la villa de Madrid, Corte de su Magestad», mandaron ellas imprimir por su orden y a su costa una nueva edición del libro de Valle. Esta vez fue la imprenta la de «Luis Sanchez, Impressor del Rey N.S.» y el año de publicación el «M.DC.XVIII».

\section{El maridaje de «erarios» con «montes de piedad»}

Oudergheste y luego Valle casaron intencionadamente la idea de crear erarios con la de traer de Italia y Flandes a España una institución mucho más antigua, la de los montes de piedad. Lo original de su arbitrio consistia en unir en una sola institución los erarios públicos y los montes de piedad privados.

- Cada ducado, según lo definieron los Reyes Católicos en 1457, contenia 3,60 gramos de oro fino, equivalentes a 0,11574 onzas troy, oro que hoy vale en el mercado de Londres el equi. valente de unas 6.000 pesetas. 
Una cosa eran los erarios, bancos públicos en los que habrian de depositarse obligatoriamente fondos congelados, como los adscritos a las fianzas de pleitos o las herencias vacantes, o a los que habria que entregar a la fuerza un porcentaje de la riqueza de todos los súbditos. Otra distinta eran los montes de piedad, cajas de ahorro privadas cuyo negocio consistía en recibir y remunerar depósitos voluntarios de mercaderes o de ahorradores, y prestarlos a interés a los necesitados, normalmente tras depósito de una prenda. Para los autores del XVII, erarios y montes no eran la misma cosa, aunque algunos quisieran fundirlos bajo un mismo techo para poner el ahorro y la riqueza privadas a disposición de la Corona, o en todo caso para ofrecer al ahorro privado la garantía de una institución de depósito fundada con capital público y controlada por las Cortes.

Muy revelador desde el punto de vista doctrinal es el que los historiadores de siglos posteriores no hayan sabido ver la diferencia entre erarios y montes de piedad, hasta el punto de pasar por alto el que autores del tiempo de Felipe IV como Alberto Struzzi rechazaran el arbitrio de los erarios pero defendieran la libre creación de montes de piedad. Tal confusión o miopia es indicativa de una mentalidad incapaz de concebir una economia bien arreglada carente de un banco del Estado. El conde de Campomanes, cuando estudió las propuestas de erarios en la década de 1770 , los entendió como precedentes del Banco Nacional que querían crear Carlos III y sus ministros ilustrados, y que de hecho se fundó con el nombre de Banco de San Carlos y con detestables resultados finales en el reinado siguiente: institución ésta de los bancos centrales que ha resultado poco favorable a la estabilidad de las monedas, al dejar en manos de los gobiernos, no sólo el antiguo privilegio de la acuñación de moneda metálica, que normalmente adulteraban, sino también el monopolio de emisión de billetes y la financiación y colocación primeras de la deuda pública.

Los montes de piedad en cambio, al ser de creación piadosa o municipal, financiar al público con el respaldo de garantías suficientes y gozar de una administración independiente de la del Estado, no eran de por si instrumentos de inflación y adulteración de la moneda.

\section{El Monte de Piedad de Burgos y el de Madrid}

El Dr. Echevarría Bacigalupe, en su libro sobre el memorialista Alberto Struzzi acierta donde tantos otros historiadores han errado, confundidos por el dogma estatalista de creer que el dinero era creación del Estado y que la insti- 
tución de un banco central público es el súmmum del progreso mercantil. Afirma Echevarría con razón que

los montes de piedad son instituciones diferentes a los erarios, aunque se les suela confundir en su tiempo y después (precisamente, Struzzi, que es defensor de los montes, clama contra la asimilación institucional [de] que sufren popularmente respecto a los erarios) ${ }^{7}$.

Como relata Echevarría, el primer monte de piedad fue creado en Perugia en 1462. Ya he dicho que en el V Concilio de Letrán (1512-1517) el papa León $\mathrm{X}$ permitió a los montes cargar costas sobre los préstamos, pero sólo para cubrir los gastos de establecimiento y la conservación de las prendas. Los montes se veían como fundaciones caritativas y no como negocios financieros. Alejandro Farnesio, en cuya corte se encontraba el también parmesano Struzzi, intentó su establecimiento en Flandes. El gran invento desde el punto de vista de la ortodoxia religiosa, consistió en transformar el contrato de préstamo con prenda, en un contrato de censo, como base del funcionamiento de estos institutos. Pero hubo que esperar a 1618 para que los Archiduques Alberto e Isabel erigieran el primero en Amberes, monte que remuneraba el pasivo constituyendo censos al 6,25 por ciento y prestaba al 15 por ciento.

Un documento del archivo del ducado de Frias, dice Echevarría, refiere a un intento de crear un monte en el siglo xv. En 1599, un vecino de Burgos, Diego Curiel, proyectó un monte para poner remedio al decaimiento de la economía de la ciudad y el campo circundante ${ }^{8}$. En 1625 se estableció uno en Madrid por influencia de Struzzi, pero duró muy poco.

Los montes de piedad eran entidades caritativas privadas, en las que, al contrario de los erarios, ni el Rey ni sus vasallos habían de poner capital por obligación, ni había peligro de que la Corona usase los fondos o el aval de la institución para sus propios fines.

\section{EVOLUCIÓN DE LA DOCTRINA DE LA USURA Y EL INTERÉS}

El libro de Valle, criticable por su propuesta de poner el invento de los montes de piedad al servicio del reforzamiento de la confianza del mercado en la Tesoreria de la Monarquía española, tiene sin embargo valor porque distingue

' Miguel Ángel Echevarria Bacigalupe (1995), p. 199.

* Félix Sagredo, 1975, pp. 72.76. 
entre interés y usura en un siglo que tendía a confundirlos; y subraya las ventajas de un sistema financiero bien arreglado para la promoción de la riqueza.

\section{Los erarios y las usuras}

Para entender la contribución de Valle en punto a usuras es preciso recordar lo sustancial de la doctrina referente a ellas en el pensamiento teológico español. En efecto, los erarios, no obstante lo sospechoso para la tradición es. pañola de toda remuneración del dinero, habian de pagarla y de recibirla. $\mathrm{Pa}$. garian una pensión del 3 por ciento a los particulares que les entregaran fondos a censo perpetuo y del 5 por ciento sobre los depósitos que el erario pudiera devolver a su voluntad o «censos al quitar» (no como hoy, que los depósitos a la vista son reclamables a voluntad del depositante). Los erarios a su vez prestarian al 7 por ciento. Sorprende tal indulgencia hacia lo que en el fondo era un negocio bancario de remuneración del dinero.

La condena de la usura debe entenderse en el contexto de la teoria del dinero y de la ética de los contratos, cual las definieron principalmente Aristóteles y Santo Tomás de Aquino.

Según la Ética a Nicómaco del Estagirita y la Summa Theologica del Aquinate, el dinero, aun siendo muy útil para facilitar el tráfico y retrasar a voluntad las compras, era estéril en esencia, no producia aceitunas como lo haria un olivo, o corderos unas ovejas, y por lo tanto no podia pedirse a cambio de su préstamo más que la devolución del principal. El préstamo con interés era pues un contrato que obligaba una parte a pagar más de lo que recibia, lo que era contrario a la justicia.

Los doctores castellanos del xvı afinaron aún más este pensamiento. Por un lado, subrayaron que no era licito pedir pago por el mero paso del tiempo: el tiempo es de Dios, se decia, y por tanto no era apropiable ni explotable por los hombres; dicho de otra manera, para ellos el tiempo no era productivo. Cargar un porcentaje por prestar liquidez, o por aplazar el cobro o por adelanto del pago de una deuda, era pecado de usura.

Por otro, insistieron en la necesidad de que todo contrato, para ser justo, se basara en el intercambio de valores equivalentes. La condena de la usura debia entenderse, pues, no sólo en el contexto económico de la visión del dinero como incapaz de producir fruto, sino también en el contexto juridico de la teoria de los contratos.

No eran pues lícitos los contratos financieros si no implicaban la transmisión verdadera de una cosa, la compra-venta de una cosa venal. Resultó impor- 
tante para el negocio de los erarios y montes de piedad el que si se considerara lícita la constitución de un censo, con la tradición o entrega efectiva de la propiedad de una hacienda o cosa o suma de dinero, a cambio del derecho a cobrar un tanto cada año en frutos o dinero.

Para los doctores, pues, podían existir contratos en los que se pagaba un interés lícito. Parecian préstamos pero no lo eran. Los censos, especialmente los constituidos a perpetuidad, implicaban la entrega o tradición de la propiedad a cambio de la obligación de pagar una pensión vitalicia o perpetua. Asi podía entenderse que la pensión pagada a un censualista no era usura condenable, sino interés lícito constituido a cambio de la cesión de la propiedad.

La noción de interés lícito cubria otros pagos que el canon de un censo. Los tratos que hiciera el Principe, incluso los de tomar dinero a préstamo, eran en todo caso lícitos. En efecto, un tipo de contrato que tenia todo el aspecto de adelanto de dinero y cobro por el paso del tiempo era el mencionado de los asientos. Por una práctica iniciada por los Trastamara y convertida en práctica corriente por Carlos V y Felipe II, el Príncipe anotaba en la contabilidad de la Corona asientos que reconocian el derecho de un banquero a resarcirse de un ingreso futuro y determinado de la Corona en Castilla, por unos dineros que había colocado a disposición de ésta en Flandes $u$ otras partes foráneas. Normalmente los asientos se constituian a cuenta del oro y la plata que se esperaba llegarian de las Indias con la próxima flota de galeones. Lo notable es que los asientos solian llevar un interés del 7 por ciento, que no se consideraba usurario, supongo que por ser este interés mucho menor que el que cobraban los prestamistas normales.

Otro tipo de contratos suscritos por la Corona era el de los juros. Se parecian éstos más a los censos, pues se trataba de un compromiso solemne de la Corona con un particular, de pagar al adquirente del juro una pensión tomada sobre los ingresos del tributo de «millones» o sobre las alcabalas de tal o cual villa o lugar, establecido a cambio de una suma contante y sonante. También los juros llevaban una remuneración de 5 a 7 por ciento, ésta implicita.

Entre personas privadas, sólo en el caso en que existiera un verdadero servicio financiero, como el de transportar dinero a otro lugar por medio de una letra de cambio girada sobre otra plaza, era licito el interés. Asimismo era permitido el interés implícito en la «compra» de un censo, contrato por el cual un particular obtenía una pensión a cambio de entregar la propiedad de un bien raiz o mueble, incluido el dinero.

Digo interés implícito porque los asientos, los juros y los censos que se constituian entre personas privadas se «compraban» entonces de una manera peculiar, de hecho se adquirian como se hace hoy con un pensión vitalicia 
contratada con una casa de seguros. Sobre todo en los siglos xV y xvI, era normal expresar los contratos, cuyo objeto era obtener pagos regulares año tras año, de la forma que sigue: se compraba el derecho a una pensión anual de mil maravedies mediante el pago inicial de diez mil, catorce mil, veinte mil, veinticinco mil o treinta y tres mil maravedies. La pensión podía ser «perpetua», con lo cual nunca volveria al comprador o sus causahabientes la suma inicialmente cedida; o podia ser "al quitar», caso de que el trato pudiera deshacerlo cuando quisiere el pagador de la pensión o interés (no el depositante de los fondos). Se consideraba muy cara la compra por un particular de una pensión (o muy barato el préstamo que ese particular concedia) cuando se adquiría por treinta y tres mil o veinticinco mil el millar y barata por diez mil el millar.

Hoy dia, en el negocio de compra de una pensión vitalicia mediante el pago de una prima única, calculariamos este valor a la inversa, como empezó a hacerse en el siglo XVI y se generalizó en el xvII, cual vemos en el libro de Valle de la Cerda. Diriamos hoy que el valor de la pensión resultaba de capitalizar la renta a tanto por ciento. Cuanto más alto el porcentaje al que se capitalizaba el censo, menor habria de ser la prima única inicial para obtenerlo, y viceversa ${ }^{9}$.

La prima única inicial para el censualista (prestamista), inversor o comprador de un censo de veinticinco mil el millar se calcularia hoy sobre la base de un interés del 4 por ciento (si dividimos 1.000 por 25.000 , da 0,04 ) y resultaria mal negocio para el censualista, es decir, el que que entregara la tierra en explotación a cambio de un canon o renta, o comprara con una prima única una pensión perpetua (o en realidad diera una suma en préstamo para obtener un interés); porque habría de calcularse un valor capital muy alto a la tierra, la prima única o el capital necesarios para obtener el canon, la pensión o el interés.

Para el censatario (o prestatario), por contra, un censo de 25.000 al millar o al 4 por ciento resultaria buen negocio: recibiria un capital por valor de veinticinco mil y tendría que pagar sólo mil anualmente de canon, pensión o interés. Es decir, un censo capitalizado 4 por ciento seria muy conveniente para el ce. satario que obtuviera o legara un derecho de usufructo sobre un inmueble, heredad o cortijo, que se comprometiera a pagar una renta perpetua a cambio de una prima única, o que recibiera una suma de dinero en préstamo a cambio de pagar un interés anual.

"El comprador de un censo puede ser persona distinta de quien lo vaya a disfrutar. Un noble acaudalado podia constituir un mayorazgo vendiendo a censo su propiedad, para que sus herederos recibieran la pension. En la actualidad, los bancos constituyen a censo un fondo de pensiones para sus empleados y el Banco de España insiste en que calculen la capitalización de dicho fondo al 6 por ciento, es decir, a $16.666 \mathrm{el}$ millar, en vez de como venian haciendolo al 8 por ciento, o $12.500 \mathrm{el}$ millar; quiere el Banco de España que se doten más generosamente esos fondos. 
Un censo de catorce mil el millar era más barato y conveniente para el censualista o prestamista de tierra o colocador de dinero, y más caro para el censatario o prestatario, pues implicaba que el censualista recibiria un interés del 7,1 por ciento, mucho mayor que el 4 por ciento implícito en un censo de 25.000 el millar.

Un censo de «diez el millar" se consideraba casi usurario por parte del censualista o prestamista, pues implicaba un interés del 10 por ciento: en este último caso, el censatario o perceptor de la renta, fuera ésta vitalicia o perpetua, habría comprado por poco dinero un rédito o interés considerablemente mayor que el de los juros normales.

Puede sorprender que el valor de los censos perpetuos se capitalizara sobre la base de un interés menor que el de los censos al quitar. Es decir, los perpetuos se pagaban por un precio al millar más alto que los al quitar, por ser éstos amortizables a voluntad del censatario, prestatario o asegurador, que podia devolver el principal cuando quisiera; y por ende la previsible más larga duración del beneficio de recibir pensión o interés en el caso de los censos perpetuos.

Hoy dia en el negocio bancario los préstamos no suelen ser perpetuos ni al quitar: son por un plazo fijo; o a la vista, devolvibles a voluntad del depositario. Por ello, el interés de los depósitos a la vista suele ser menor que el de los de ahorro o a plazo, mientras que los censos al quitar se calculaban con un interés mayor que los perpetuos, que el erario no podía devolver a su conveniencia.

\section{La doctrina barroca ante la práctica mercantil del interés y la usura}

Desde el punto de vista del análisis económico es un error la condena de los contratos puros de préstamo de dinero o bienes, y de los recargos o descuentos por el paso del tiempo. La liquidez es un factor de producción precioso. Si fuésemos capaces de prever perfectamente el futuro y de organizar nuestros contratos de tal manera que casaran siempre exactamente nuestros cobros y nuestros pagos, no necesitaríamos caja. Si viviésemos eternamente, el tiempo no tendría precio, pues podriamos ser, parafraseando a Marx y Engels, campesinos y ganaderos un año, industriales otro, críticos y escritores más adelante, sin tener por qué impacientarnos pues el momento llegaria de hacer lo que nos pluguiera. La incertidumbre exige liquidez y nuestra corta vida nos hace preferir el goce presente al goce futuro. Todo ello lo enmarcamos hoy en la noción de coste de oportunidad, por el que exigimos compensación cuando renunciamos, bien la liquidez, bien al goce presente.

La vida mercantil no entiende de errores analíticos. Pese al deseo de los padres doctores de ignorar las razones de la liquidez y el precio del tiempo, re- 
sultaba muy dificil impedir que los individuos pagasen y cobrasen por ambos, liquidez y tiempo.

Por ello, en la práctica no era nada fácil distinguir un contrato o un préstamo usurario de aquel que sólo redituaba un interés lícito. Cuanto mayor la cuantia del porciento o menor cantidad de maravedies que habia que entregar inicialmente para cobrar un rédito, más fuerte era el olor a azufre del contrato; mientras que un porciento reducido inclinaba a considerar no usuraria la entrega de dinero por el censualista al censatario.

Sin embargo, también podia resultar lícito un interés alto, si se pagaba a posteriori en compensación de un daño sufrido por la cosa prestada, o incluso por el daño sufrido a causa del retraso en devolver el principal cuando había fecha pactada. Sto. Tomás y otros padres aceptaron que se considerara lícito el contrato que incluyese, bajo forma de interés, una compensación por daños no previstos en la cosa prestada o entregada a censo, lo que se llamaba damnum emergens. Era normal que si la mula que me habia prestado el vecino volvia tuerta hubiese yo de compensar el daño: igualmente si devolvia tarde el dinero prestado.

Cosa distinta era la ganancia perdida por no tener el prestamista a su disposición el bien o el dinero prestados, justificación especiosa para los más autores, que corria bajo el nombre de lucrum cessans. Como el beneficio futuro era siempre aleatorio (y no sabian ver que el tipo de interés del mercado era una estimación de los beneficios futuros probables), consideraron muchos $\mathrm{Pa}$ dres que no podía cobrarse nada por ese lucro cesante, y que no era trato equivalente pagar dinero por haberse deshecho un sueño o mera esperanza de beneficio.

Podia haber usura incluso en contratos que no fueran de préstamo, sino de compraventa o arriendo. Respecto de los contratos usurarios pero no monetarios, citaré al P. Martin de Azpilcueta en su Comentario resolutorio de usu$\operatorname{ras}(1557)$ :

todo comprador, todo arrendador, todo trocador que, por pagar de antemano y antes de recibir el provecho de lo que se compra, arrienda o trueca, da algo menos del justo precio más bajo para paga entera dello, es usurario.... Síguese, quanta razon ay de rogar a Nuestro Señor que dé arrepentimiento con restitu. cion a los que... les llevan mas del justo precio más alto por darles plazo para la paga dello, y aun tanto más llevan cuanto mayor es el plazo ${ }^{10}$.

10 Martin de Azpilcueta, Doctor Navarro: Comentario resolutorio de usuras, Salamanca, 1557, n. 5. 26-27. citado por Bernardo Alonso Rodriguez y Antonio Garcia Garcia (1993), pp. 17.18. 
Respecto a las usuras en los cambios, citare a Fray Tomás de Mercado, en sus Tratos y contratos (1569):

no dejan de pecar en esta tecla mil cambios, que se dan sin cambio ninguno ni trueque. Estos son los que se llaman secos, cuando entre el un entrego y el otro no hay distancia de lugar, sino sola dilación de tiempo.

Distinguia Mercado, como todos esos autores, la usura manifiesta, de la «paliada» o disimulada.

Seria cosa prolija singularizar asi todas las materias do se puede cometer este vicio [de la usural y en efecto se comete. Solo baste que no hay negocio humano que sea trato y granjeria do no pueda entrar y do muchas veces en realidad y de verdad no entre y se halle disfrazado y disimulado como malhechor. Dondequiera que hay mas o menos del justo precio, junto con algunas esperas o anticipación de pagar, hemos de sospechar de vebemente haber usura, la cual hallara fácilmente agachapada, como liebre, si se espulga con sagacidad el contrato, mayormente que su mal olor es tan grande que luego se descubre. $Y$ hemos de advertir que de todas las maneras que dijimos se hallaba manifiesta, se halla también paliada ${ }^{11}$.

Más peliagudo era el trato de los erarios. Era cosa de saber si el interés equivalía a algún bien tangible entregado a cambio. Por ello, la única salvación del contrato de entrega de un capital residía en que se constituyera como censo.

En efecto, decia Tomás de Mercado:

Entre estos censos, unos son perpetuos, que duran para siempre y llaman irredimibles, que tienen obligación perpetua de pagarlos y ninguna libertad para rescatarlos; otros hay redimibles, que se pueden quitar o eximirse y redimirse la persona de ellos. Estos en particular fueron los que infamaron el contrato de usurario, y no dejaba de tener el escrúpulo algún color, que, como la gente veia

1 Fray Tomas de Mercado: Suma de Tratos y Coniratos, en la edicion de Nicolas Sánchez Al. bornoz (Madrid, 1977), vol. II. pp. 566-7. La edición principe de 1569 se titulaba: TRATOS Y CONTRATOS DE MERCADERES y tratantes discididos y determinados, por el Padre Presentado Fray Tomás de Mercado, de la Orden de los Predicadores. Con licencia y privilegio real EN SALAMANCA. Por Mathias Gast. Año de 1569. Esta tassado en cinco reales. La edición de 1571, que es la completa, porque Mercado le añadio dos libros sobre la ley natural y es la que empleamos, se titula: SUMMA DE, / TRATOS, Y CON-/TRATOS, COMPUESTA POR/ el muy Reuerendo Padre Fray Thomas de Mercado/ de la Orden de los Predicadores, Maestro en/ sancla Theologia. Diuidida en/ seys libros./ ANADIDAS A LA PRIMERA/addicion, muchas nueuas soluciones. $Y$ dos libros/ enteros, como paresce en la pagina siguiente/ [Una imagen de Sto. Domingo] / Con licencia, y Priuilegio Real. / EN SEVILLA. / En casa de Hernando Diaz Impressor de Libros, / en la calle de la Sierpe. / 1571. 
que daba uno dos mil ducados y recibía cada año doscientos $y$, pasados seis o siete, le volvían sus dos mil, pareciales un genero de préstamo interesal.

La verdad es que la apariencia «usuraria» de los censos al quitar era vehemente, que diria nuestro buen Mercado; y además podia ser dañina para la República la práctica de los censos perpetuos, como dijeron las Cortes de Castilla, según las citó el propio Mercado:

Otrosi decimos que como las necesidades del Reino han ido y van cada dia en crecimicnto, y como no hay otra manera de socorrer la gente, si no es tomando censos sobre sus haciendas, y éstos los hallan tan baratos [al millar], como son a diez por ciento, que muchos se han dado tanto a ellos que, pareciéndoles buena manera de vivir, se han dejado de la labranza y crianza y otros tratos y grangerias en que entendian, con que el Reino era beneficiado, y emplean sus haciendas en los dichos censos, de que se siguen daños e inconvenientes.

A esto, dice Mercado, respondió el Rey como sigue (si bien no sé yo con qué efecto práctico):

Ha parecido ser justo lo que nos pedis. $Y$ asi ordenamos y mandamos que de aqui en adelante no se pueda en estos nuestros Reinos, ni en ninguna parte ni lugar dellos, vender, ni imponer, ni constituir juros ni censos algunos de al quitar de a menor precio de 14.000 maravedis cada millar [es decir, a un tipo de mas del 7,1 por ciento].

Sin embargo de todo ello, habia encontrado Fray Tomás modo de calificar el censo, incluso al quitar, como lícito, siguiendo por otra parte las decisiones favorables de los papas Urbano VI y Calixto III.

Digo que [en el contrato de censo] se merca solamente un derecho y obligación que éste hace de dar tanto cada año a su tiempo según se conciertan y se usa. $Y$ los bienes raices que se señalan sirven como de hipoteca y fiador, que, faltando $y$ no pagando, puede echar mano de ellos y venderlos y hacerse pagar... Y aqui se merca, según mostramos, un derecho de cobrar un tanto cada año o en dineros o en algunos frutos de cosecha, el cual derecho es venal y vale sus ciertos dineros.

Como el censo era un contrato en el que se intercambian cosas equivalentes, tierra por canon, dinero por pensión, el trato era lícito.

La raiz cuadrada de este punto consiste en que dar a censo no es prestar sino mercar. Y la compra, como sea de cosas venales, siempre es de suyo lícita ${ }^{12}$. 499.502.

12 Tomás de Mercado: Summa de Tratos y contratos, edición Sánchez-Albornoz, vol. II, pp. 
A Fray Tomás de Mercado, de la Orden de Predicadores, muchas cosas le serán perdonadas por su hermoso y castizo español.

\section{LA OPINION, EN FAVOR DE LOS ERARIOS}

Durante el reinado de Felipe III, muchos escritores $\mathrm{e}$ incluso las Cortes de Castilla se mostraron favorables a la creación de una red de erarios, pese a las críticas de personas entendidas, porque se suponia que serian financiados inicialmente por la Corona y porque permitirian evitar el aumento de la carga fiscal.

Los erarios en el libro de Valle de la Cerda

Volvamos al libro de Valle, con su explicito título de Desempeño del Patrimonio de su Magestad, y de los Reynos, sin daño del Rey y vassallos y con descanso y alivio de todos. Por medio de los Erarios publicos y Montes de Piedad (1618).

El libro, tal y como lo publicaron las Cortes en 1600 y lo reprodujo la misma institución en 1618, venia dividido en dos partes: la primera, el propio escrito de Valle de la Cerda; la segunda, un

SVMARIO DE LAS OPOSI-ciones que hizo a los Erarios, y Montes de Piedad, el Marques de Estepa. Las respuestas que en su satisfaccion hicieron los Contadores Francisco Salablanca y Luys Valle de la Cerda, cada uno de por si, van puestas al fin, de cada oposicion en la hoja que se alega.

El trabajo de Valle de la Cerda propiamente dicho consta de 29 capitulos. Contiene mucha de la materia que luego veremos repetida en los escritos de las Cortes y disposiciones legales: de las ventajas que tiene su fundacion, las ganancias que supondrian para la Real Hacienda, la reducción de las usuras y de la mala moneda, y las razones por las que no habria que temer que el Rey echara mano de los recursos de los erarios cuando le apretase la necesidad.

En algunos puntos quiero detenerme. El primero es la atención que presta a la licitud moral del pago de un canon sobre los censos, que formarían la mayor parte de las operaciones pasivas y activas de los erarios (además del giro de las letras de cambio). La primera cuestión es si era lícito y conveniente pagar el 5 por ciento a los censos pasivos al quitar en los erarios. 
Este censo de cinco por ciento o veinte mil el millar le han estimado los Doctores por justo, y proporcionado,... fundandose, en que por derecho parece valer vna heredad lo que renta en veinte años..., porque aunque los juros y censos de rze o 7,1 por ciento son justos en conciencia, pero no parece que estan justificados en $\mathrm{si} ;$;... porque la tierra que ordinariamente produze cinco por ciento, quitado el trabajo, cuydado, y costa, se puede tener por fertil. Y si el dinero da sin trabajo, ni otra costa, siete por nouenta y ocho [es decir, 7,1 por ciento ó 14 mil maravedies el millar], claro es que se menospreciará la tierra mas fertil.

Si además con estos cánones moderados el efecto de los erarios fuera el de bajar los intereses, ello tendria una repercusión benéfica en la creación de riqueza real.

$Y$ como desta admirable inuencion de los Erarios, y de venir a embeuer en si todo el manejo de la contratacion en general, resulta el reduzirse a ellos el trato de dinero de la Republica a tan moderado precio, se sigue que boluera mas facilmene a su estado la labrança, que es la natural grangeria por si misma neçessaria, como dize Aristoteles. (Ff. 36-37.)

Los censos perpetuos los habrian remunerado los erarios con un 3 por ciento, un tipo de interés más bajo que el de los censos al quitar, pues éstos eran rescindibles a voluntad del erario e inciertos para el rentista. Razón adicional era la gran demanda de estas inversiones perpetuas por quienes querian crear fundaciones y mayorazgos $y$

buscan esta perpetuidad, reboluiendo en la imaginacion, en que lugar. o parte emplearan su dinero que tenga la renta del [censo] que compraren mas firmeza y puntualidad en la paga.

Algunos, añade Valle de la Cerda, «dan por cada uno de renta... veinte y cinco hasta cinquenta de principal», es decir, se contentan con un 4 ó un 2 por ciento por ciento de rédito.

A esto podían añadir los erarios que la oferta de este tipo de censos a perpetuidad terminaria en algún momento.

Y aunque a los Erarios al principio, para tener mas fuerça les conuiene cargarse de censos perpetuos; pero despues cerraran la puerta: y quien al principio no los comprare, no los espere: aunque quiera fundar mayorazgos, ni otras memorias, porque los Erarios no se cargarán sino a menos de tres por ciento. (Ff. 37-8.)

De la Cerda destacó además el margen de intermediación como atractivo adicional de los erarios para sus fundadores. 
Vna de las grandezas de los Erarios, que a la primera vista parece imposible, y contra conciencia, porque dezir que procuramos cayda de vsuras; y dar y recibir a censo a cinco y a seis (precio tan justificado y permitido en Derecho, con verdadera traslacion de dominio) y prouar aora que sin passar año, sino que en el instante de dos contratos,... que es el dar dinero a censo el Erario, y recebir a censo, le resultan veinte de ganancia. (F. 39.)

En efecto, si el erario "presta» cien ducados a Juan, a cambio de que pague un 6 por ciento anual; y viene Pedro a depositar su dinero al 5 por ciento, el erario puede darle el pagaré de Juan por 120 ducados. La ganancia en un instante es del 20 por ciento. Por eso sería tan inagotablemente bueno el negocio bancario si no hubiese límite de buenos pagadores y de confiados de positantes.

Dos puntos interesantes quedan en esta plática de Valle de la Cerda: la seguridad de los nuevos establecimientos y su capacidad de crear nuevos instrumentos financieros.

Para empezar, la confianza: quiere responder a quienes dicen

que el pueblo no se fiara dellos por temor que en algun tiempo el Rey, o Principe superior los despojará del dinero que en ellos entrare, y por esto no tendran credito. (F. 83.)

Son muchas las razones que da para decir que los erarios de España tendrán tanta firmeza como el banco de San Jorge de Génova o el Monte de Piedad de Florencia: la principal (y poco convincente) es que a los reyes de Castilla no les conviene destruir un instituto que les desempeña....

En cuanto a la constitución de una red bancaria nacional, leemos:

Constituydos pues, y fundados estos Erarios en todos los Reynos de su Magestad vendran con el tiempo de si propios a buscar cada vno el credito y correspondencia del otro, $y$ de todos los que pudiere; y exercitará las letras de cambio de un Erario a otro, a muy moderado precio, y conforme a conciencia. (F. 134.)

No era manco banquero el antiguo pagador del Duque de Parma en Flandes.

\section{La famosa Consulta de 1619}

Caído el Duque de Lerma le sustituyó su hijo el de Uceda, quien resultó tan incapaz como su padre para el gobierno del pais, y tan capaz como él para 
el gobierno de su fortuna personal. Expresado por Felipe III, pese a su hipocondria, el deseso de acercarse más a las labores de gobierno, se planteó una lucha de influencias entre su confesor, el jesuita Luis de Aliaga, y don Baltasar de Zúniga, el presidente del Consejo de Estado y protector de Olivares. Uno de esos tres, Uceda, Aliaga o Zúñiga, propició un época de notable libertad de expresion, por deseo de distinguirse de su padre si fue Uceda, o de alentar las críticas al desgobierno de Lerma y sus protegidos si fueron Aliaga o Zúñiga. Ello se notó sobre todo en la «Consulta hecha por el Consejo Real a Su Magestad sobre el remedio universal de los daños del Reino y reparo dellos. Madrid a $1^{\circ}$ de febrero de $1619{ }^{\prime 13}$.

Alrededor de tal consulta se arracimaron publicaciones y memoriales de arbitristas. Esta vez la ocasión institucional no fue una sesión de Cortes, sino la mencionada iniciativa de los nuevos consejeros del Rey. Baste recordar que son de 1619 las publicaciones de Fernández de Navarrete, Conservacion de Monarquias, y de Sancho de Moncada, Restauracion Politica de España y Deseos Publicos, de finales de ese año o principios del siguiente el manuscrito de la obra que Geronymo de Cevallos publicaría en 1623 con el beneplácito del Conde Duque de Olivares, «Arte Real», en que precisamente Cevallos volvía a proponer se fundaran erarios y montes de piedad; y del año 1620, memoriales como el titulado, Para suplicar al Rey que se probiba la entrada a las mercaderias labradas fuera del reyno la salida de lanas y materiales en que se ban de ocupar y trabajar los naturales.

Para que renaciera el asunto de los erarios en las Cortes, hubo sin embargo que esperar a que la temprana muerte del aún joven Felipe III pusiera a la cabeza del reino al jovencisimo Felipe IV y su mentor el Conde de Olivares.

\section{LA RESISTENCIA DE LAS CORTES DE CASTILLA}

Las primeras Cortes del reinado de Felipe IV se iniciaron el 16 de junio de 1621. Los procuradores Juan de Verástegui y Mateo Lisón y Biedma pedian la creación de una comisión mixta de ministros y procuradores para preparar un gran programa de reforma. Pero el nuevo valido, don Gaspar de Guzmán y Pimentel, Conde de Olivares, tenia otros planes y optó por crear una Junta

"Tal es la interpretación de R. A. Stradling (1989), pp. 32-34. J. H. Elliott (1980), pp. 136 y ss., presenta una excelente descripcion de lo que me he atrevido a llamar ela batalla de los erarios». Debo a Elliott la identificación de Juan Lopez Ugarte como el último superviviente de los cuatro defensores del sistema en tiempos de Felipe II. 
Grande de Reformación en agosto de 1622, pues ésta la presidia el Rey con su valido y no el Presidente del Consejo de Castilla.

El 28 de julio de 1621, Juan López de Ugarte, el último superviviente de los cuatro (con Oudegherste, Rottis y Valle) que habian defendido los erarios bajo Felipe II, remite, posiblemente al Conde de Olivares, un

Memorial en el que se insta por el establecimiento de los erarios públicos o montes de piedad que habia ideado Luis Valle de la Cerda, y donde da noticias de la forma en que se desarrollaron las primeras gestiones de estas materias ${ }^{14}$.

En la sesion de 16 de octubre de 1621, el procurador por Córdoba don Pedro de Angulo dijo que

tiene noticia que en las Cortes que vltimamente se disolvieron, el Reyno trato de poner por obra lo que en otras tenia acordado de instituir los herarios y montes de piedad, conforme al libro de Luis Valle de la Cerda, y por parecerle que conbendría irlo disponiendo poco a poco, acordó se instituyesen primero los montes de piedad, por ser la parte mas facil y suave de executar.

El valido del nuevo Rey aún no se habia puesto en movimiento para apropiarse de la idea con el fin de allegar más medios para el Estado.

\section{Iniciativas de Olivares en 1622}

En el mes de octubre de 1622 escribió el Rey cartas a las ciudades principales de Castilla desde Valsain de Segovia, en las que hacia dos propuestas unidas, que fueron las responsables de hundir el proyecto de los erarios e incluso el de los montes de piedad: una, la de crear erarios cuya financiación principal se basara en un depósito obligatorio de un porcentaje de la riqueza de los vasallos; otra, la de sustituir los millones (y su acompañamiento de condiciones a las que las Cortes sometian a la Corona a cambio de votar aquel impuesto) por un repartimiento entre las 15.000 villas y lugares castellanos del coste de «una armada de 15.000 hombres» ${ }^{15}$. Eran éstas dos ideas de su valido, don Gaspar de Guzmán y Pimentel, Conde de Olivares, quien mandó en-

is Documento XXII de La Junta de Reformación. Documentos... transcritos por D. Angel González Palencia, 1618-1625 (Valladolid, 1932), pp. 379.408. La fuente es Archivo General de Simancas, Consejos, libro 1434, folios 134 y ss.

is C.f. John H. Elliott y Jose F. de la Peña (1978): Memoriales del Conde Duque de Olivares. Madrid, 1978, pp. $15-17$ y passim. 
viar «a las Ciudades con Voto en Cortes» la dicha carta «tocante al remedio de la Monarchia».

De esta carta o cédula, remitida por Pedro de Contreras, secretario de Cámara de Felipe IV, a diversas ciudades con representación en Cortes, a partir del día 21 de octubre de 1622, quedan dos versiones principales: una, fechada en 29 de octubre y dirigida al «Concejo, Justicia, Regidores, Caualleros, escuderos y oficiales y hombres buenos de la muy noble ciudad de Valladolid»; y otra, la que unos cuarenta años más tarde recogió Martinez de la Mata en su Octavo Discurso en el que proponia «el medio fácil, y suave» de la restau. ración de la Real Hacienda, esto es, los consabidos erarios ${ }^{16}$.

Veamos la dirigida a Valladolid. En ella, tras agradecer la respuesta de las autoridades de esa ciudad de 14 de septiembre de 1622 a una anterior del Rey de 3 de septiembre, dice haber procurado considerar

menuda y atentamente las causas porque ha venido este reyno al estado que tiene, y ruina que le esta amenaçando y los medios que podran obrar en su reparo, con vista de papeles que se han dado y con otras noticias particulares que se an adquirido, y con larga conferencia, discusion y deliberazion de las personas de la Junta, y otras que con particular cuidado y trabajo se a desvelado en ello.

En consecuencia dice que sha parecido que convendra disponer y hordenar lo siguiente». Y una de las disposiciones siguientes es precisamente la refe. rente a los erarios, pues «en ellos como en una tabla vnica se libra la saluacion de la Monarchia».

En la dicha carta del Rey, se empezaba por decir sobre los erarios que

se a tratado diversas vezes de su institucion y vso, particularmente en tiempo de los Reyes, mis Ses abuelo y padre, y estubo resuelta, si bien no se pudo executar por no hauer hallado medios para su dotazion, por las grandes obligaciones en que se hallaron. (397).

A continuación detallaba la carta las diez ventajas del nuevo arbitrio.

La primera era que

augmentara grandemente la labrança y la criança...asi en los años esteriles sobrellebando la costa, como en los abundantes entreteniendo los fructos hasta que tengan precio.

in Pueden verse las respuestas de diversas ciudades en Archivo General de Simancas, Patro. nato Real, caja 91. 
La segunda era que «augmentará la fabrica de todo genero de mercadu. rias» porque los erarios darán socorro para «comprar materiales y costear las labores». Añade la carta algo que se deduce del hecho de que los erarios según esta propuesta gozarian de un estanco: «que nadie ha de poder dar, ni reçiuir a çenso mas que a çinco por çiento». No se habla aqui del siete para las operaciones activas de los erarios, como aparecerá más tarde a lo largo de las discusiones de Cortes.

La tercera era que se quitaban «las compras y las ventas al fiado», con lo que se reducirian los precios. La cuarta, que los vasallos podrían pagar puntualmente las rentas reales. La quinta que «se estorbaran las quiebras de los mercantes y tratantes» por no «hallar dinero con moderados intereses». La sexta, que cesarian la usuras. La séptima, que «remediará mucho la saca de la plata y oro fuera del reyno. La octava, que «se quitaran los asientos de los estrangeros, que es la cosa que mas estragado tiene oy el caudal y credito de mi Real Hazienda». La novena, que los erarios bastarían para desempeñar la dicha $\mathrm{Ha}$ cienda. Y la décima, que el depósito de moneda de vellón en los erarios a censo del 3 por ciento, sacaria esa moneda de la circulación; o como entonces se decia, los erarios podían servir como

medio para la reduccion y consumo de la moneda de vellon, vnico y lastimoso estrago desta corona y sus vasallos.

Me detengo un momento en esta ventaja décima. No explicaba la carta si los erarios habian de prestar en vellón a su vez descontando letras, o si, guardando el vellón, reducirian la circulación de moneda. Pero si es cierto que, cada vez que el Consejo de Castilla amagaba una devaluación del vellón respecto de la plata, quienes tenían vellón acumulado lo sacaban a la plaza, con recrudecimiento de la inflación, lo que se evitaría si lo depositaran al peso de cobre en los erarios.

El problema sin duda estaba en la financiación de los erarios públicos. No bastaba que todas las rentas del Rey entrasen en los erarios, ni los depósitos judiciales. Era necesario

que todos los vasallos desta corona, asi eclesiasticos como seglares, en que entran arzobispos, obispos \& \&. \& $\&$., compren por una vez de los herarios lo que montare la veintena parte de sus haziendas, o rentas, $y$ que el herario les funde çenso perpetuo a razon de tres por ciento.

No concebia la carta que pudiera haber cuestion, vista

la suavidad del medio, pues ningun particular da hazienda ni disminuye la suya. sino solo traslada el empleo de aquella cantidad. 
Las Cortes no iban a ver este depósito forzoso con ecuanimidad, ni tampoco el reparto de

treinta mill soldados entre quince mill y tantos lugares que tiene esta Corona, cauen a dos soldados por lugar, que montan ciento y quarenta y quatro ducados.

Pasada la mitad del siglo, Martínez de la Mata, en su Octavo Discurso, citó grandes pasajes de otro ejemplar de esta misma carta o cédula que debió llegar a alguna ciudad andaluza, de los cuales, por no repetirme, traeré aqui los que Mata escribe insertando los erarios en el marco de la politica proteccionista típica de estos «mercantilistas», denominación en la que incluyo tanto a Olivares, como a Cevallos, como al propio Mata. Comienza asi sus citas este último:

Por los daños que se sienten en la entrada de mercaderias en este Reino, y de la salida de algunas, deseando asentar con seguridad el comercio dellos, afianzar que su sustancia y virtud la gocen los vasallos, se dispone esta mate. ria... Y porque no bastaria poner el gobierno interior del Reino en este estado, para librarle de la ruina que se teme, si no se restaura el trato y el comercio, que es el único fundamento de la conservación y aumento de las Monarquías; y se disponen los medios necesarios para ello, particularmente el detener el dinero, buscando alguno para que no salga deste Reino; y que sus naturales se conserven, teniéndole pronto y a mano para sus socorros.

Ese medio, naturalmente, era el de los erarios y montes de piedad ${ }^{17}$.

\section{Los erarios en el libro de Geronymo de Cevallos}

$\mathrm{Al}$ año siguiente del envío de la cédula de Valsain se imprimió el libro de Cevallos ya mencionado. Pero, según Elliort, el Conde de Olivares, a quien el autor se lo dedicó al publicarlo, lo había visto ya en manuscrito bastante antes, quizá en 1619 18: es un libro que a Elliott le «parece un anteproyecto del programa de reformas que adoptaria Olivares» ${ }^{19}$. Su título era:

ARTE REAL / PARA EL BUEN GOVIERNO / de los Reyes, y Principes, $y$ de sus Vasallos. En el / qual se refieren las obligaciones de cada uno, con los prin/-cipales

1: Memoriales y Discursos de Francisco Martínez de la Mata Edicion y Nota Preliminar de Conzalo Anes (Madrid 1971), pp. 234 y ss.

1* El catalogo de la Biblioteca de Olivares en El Escorial recoge la existencia en las colecciones del valido de un manuscrito de este libro.

is J. H. Elliott $(1990)$, p. 138. 
documentos para el buen gouierno; / CON VNA TABLA DE LAS MA-/terias, reduzida a trezientos Aforismos de Latin y Romance. / Dirigido a la Catolica Magesiad / del Rey don Felipe IIII. N.S Monarca y Emperador de las / Españas, no reco. nociente superior en lo temporal / LEGE ET RECE, / POR EL LICENCIADC GERONYMO DE ZEVA / llos, Regidor de la Imperial ciudad de Toledo en el rango. $y$ asiento de / Ios Cavalleros, y unico Patron del Monasterio de los Descalcos / Franciscanos de la dicha ciudad. / Año M.DC.XXIII. En Toledo. A costa de su autor.

Este libro es tan buena muestra, como casi todos los de arbitristas del siglo xvir, de la inepcia y cortedad de miras del mercantilismo castellano, enlodado en su mayor parte en un confuso proteccionismo.

Pero no es éste el objeto de mi comentario, sino los erarios, cuestión en la que Ceballos muestra mayor sensatez. Así, rechaza la idea de que hava de establecerse un registro de las haciendas para luego obligar a que los castellanos adinerados depositen un porcentaje en los erarios, porque, dice, al descubrirse el monto del patrimonio de los asi encabezados «se desacreditarian los hombres de negocios, cuyas haziendas consisten mas en credito, $y$ opinión comun, que en la verdad» (f. 30 r. y v.). El capital de partida de los erarios, que se depositaria a censo en los dichos erarios, habria de venir de capitales donados u ociosos: un tercio de los abintestatos, la mitad del quinto de las testamentarias. la mitad de las mandas caducas, depósitos judiciales y otros.

\section{El Consejo de Castilla, a vuclias con la usura, en 1623}

No es objeto de mi trabajo el describir en todo su detalle la discusion doctrinal, que relata Carrera Pujal, sobre la propuesta de crear una red de crarios, en la que Cellorigo, Fray Juan Castro, Gerardo Basso y Fernández de Navarrete se mostraron a favor de los erarios publicos; y nuestros viejos conocidos $\mathrm{Li}$ són y el Marqués de Estepa, en contra ${ }^{20}$. Sí lo es el efecto de tal polémica en la lenta transformación del concepto de usura ilegitima en interes normal y aceptable, y el subrayar el papel institucional de las Cortes en esa polémica.

Doctrinalmente hablando, la idea de crear una institución financiera que recibiera y prestara a censo no incurria, según hemos visto, en la condena de la usura.

Sin embargo la cuestión había de preocupar. En la sesión de 13 de mayo de 1623, secreta como todas las de Cortes y con procuradores diferentes de las de años anteriores, se toma nota de un «billete» que envía el aliado y

20. Vide Carrera Pujal (1943.451, vol. II, pp. 137, 514 y 541 


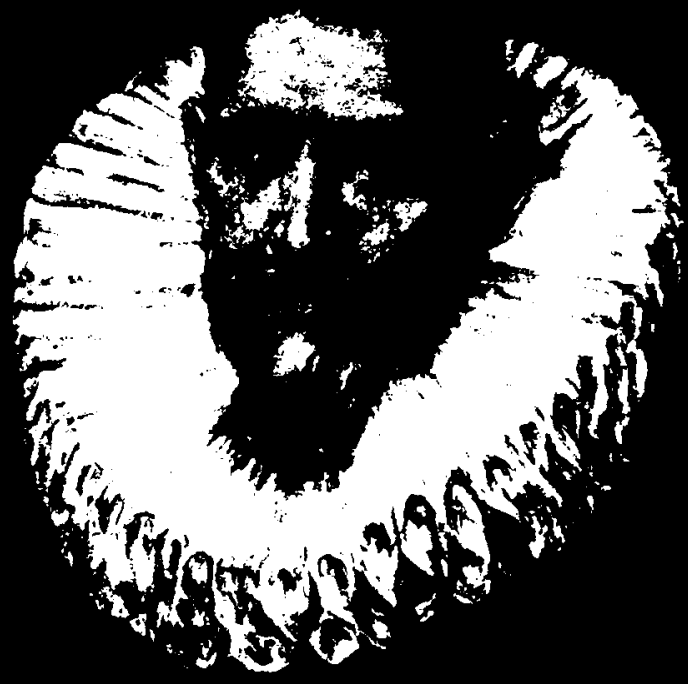

Jerómmo de Cehallos, Fil Greco. Museo del Prado, Madrid. 
hechura del Conde de Olivares, el Presidente del Consejo de Castilla, D. Francisco de Contreras. Este largo escrito, que consta de XXV capitulos, toma de la página 129 a la 209 del las Actas transcritas de dichas Cortes, y lleva el titulo de: «Advertencias del estado en que estan el Patrimonio Real y el Reino y de las medidas por donde se podria tratar su reparom.

El tema que nos interesa comienza en el capitulo VIII, que lleva el encabezamiento "Que los erarios es el remedio caual y uniuersal...» y sigue en el IX en el que ya se definen las operaciones:

Que consiste en receuir dineros a cinco por ciento al quitar, y a tres por ciento a censo perpetuo, $y$ darselos al siete por ciento al quitar...que es el valor ordinario de los juros.

¿Cómo se justificaba teológicamente el 7 por ciento al quitar que cobraban los erarios en sus operaciones activas? El Presidente del Consejo de Castilla lo justificaba de dos maneras. El diferencial iría a cubrir los gastos de administración, además de ser un seguro contra las pérdidas causadas por créditos morosos y perjudicados. Este diferencial podía considerarse pues como una cobertura contra el «damno emergente» que por témino medio iba a sufrir el erario.

También empleaba el documento la noción de «lucro cessante» para justificar el margen susodicho, cuando el lucro esperado fuese cierto:

quicren lo herarios no darlo todo a mercaderes, sino darlo a vn cauallero o ganadero o comunidad religiosa o otra persona que no tenga por oficio trato publico, en este tal se justificara la ganancia también en el lucro cesante, porque pudieran los herarios darlo a mercaderes en trato de compañia con las calidades y seguridad dichas donde estaua seguro, y no lo hacen por acudir al socorro de la necesidad de aquel particular, $y$ asi es justo que satisfaga la ganancia que dexaren de tener, $y$ la qual fuera tan cierta que se puede reputar por perdida no auerla gozado. (154).

En resumen, ique el lucro cesante se convertía por arte teológica en daño emergente! Es pena que aún estuviera tan lejos el descubrimiento de la noción de coste de oportunidad.

La resistencia de las Cortes de 1623

En el documento enviado por el Presidente Contreras, página 168 de ese volumen de Actas de Cortes, aparece una de las dos cuestiones que echaron a pi. 
que el arbitrio: una, que los cien mil vasallos mas ricos, con haciendas de veinte mil ducados o más, entregaran a los erarios en cinco años mil ducados cada uno «a censo perpetuo a raçon de a tres por ciento» 21; la otra, que se repartiese entre las villas y ciudades de Castilla del coste de esa «armada» permanente de treinta mil soldados.

Se entiende, pues, que las Cortes, y las ciudades representadas en ellas por los procuradores, se resistieran a la expropiación de tan crecidas cantidades. No sólo no habia confianza en que la Corona se abstuviera de apropiarse de tales fondos y que los erarios se vieran forzados por decisión soberana a suspender el pago de los censos, sino que el dinero era de cada uno y cada uno tenia que poder colocarlo donde le viniera en gana. El presentar este pleito como una lucha de poder entre una Corona necesiatada de fondos y una oligarquia egoísta, es no entender las ventajas para la Corona y el pais de respetar la institución de la propiedad privada.

Esta natural resistencia explica que, una y otra vez, leamos que las ciudades sólo permitian al procurador en esta materia «boto consultiuo, dexando el decisiuo a su ciudad", como lo declaró Juan de Berga, procurador por Valladolid, el 30 de marzo de 1623, y de la misma forma el otro por Valladolid, los dos de Jaén y uno de Córdoba, Cuenca y Segovia.

Olivares, en su afán por romper la resistencia de las Cortes, llegó incluso a hacerse elegir por Madrid a la de 1623, y también fueron procuradores aliados suyos servidores de la Corona. Es reveladora la reacción de los «Señores Don Juan Temino y Luis Caxa», procuradores por Guadalajara y Cuenca.

digeron que se nombren comisarios que digan a Su Señoria Ylustrisima...el repato que se hace en orden de lo que en el Reyno dijo de palabra el Señor Conde de Olivares [pidiendo la creación de erarios y pago de treinta mil soldados], y que para cualquier cosa, por ser tan grave e importante lo que se trata, es menester tiempo para comunicarla con letrados de ciencia y conciencia y cumplir con ella y las delegaciones que se tiene. 13691 .

El Rey tomó la decisión de aprobar los erarios pese a tanta resistencia y en la transcripción de las Actas de Cortes aparece una Cédula de 20 de octubre de 1623 y luego una Instrucción sobre fundación e institución de los erarios que deberia haber zanjado la cuestión.

De hecho, el 31 de mayo de 1623, el Presidente del Consejo de Castilla envia un billete que reza:

? He calculado que el oro contenido por 5.00 o dacados oro de la época equivaldria hoy a unos 30 millones de presetas. 
La institucion dellos y sus leyes estan resueltas por S.M. y publicandose asi en la caueza de las pragmaticas que se promulgaron como el Reyno lo deue tener aduertido para no tratar de parte, supuesto que S.M. pudo sin el Reino resolver.

El mandar conuocar a las Cortes solo fue para darles noticia como vna de las dotaciones de los erarios avia parecido que fuese la uenta de la veintena parte de las haciendas, de cuya execucion S.M. no ha sido servido tratar sin que el Reino le confiera y bea si se le ofrece algun inconbiniente...pero no para que tratase de los puntos de la institucion y leyes de los herarios, pues como ya resuel. tos por S.M. no tienen que entrar ni salir el Reino. 1377 .

Al final, nos dicen Elliott y De la Peña, el 7 de febrero de 1626, el Rey aceptó que las Cortes pusieran como condición, recogida en «el memorial de apuntamientos» para concederle los «millones» que Olivares habia querido sustituir por un impuesto no condicionado, al contrario del de millones), que los erarios se fundasen exclusivamente con capital entregado por la Corona, con lo que el arbitrio se fue a pique. Los erarios, que habian sido apoyados por las Cortes mientras tuvieron aspecto de Monte de Piedad, fueron rechazados victoriosamente por ellas cuando Olivares quiso convertirlos en banco nacional, fundado con una leva forzosa de capital privado.

\section{El parmesano Alberto Struzzi y los montes de piedad}

Eran muchos los que defendian la conveniencia de que apareciesen instituciones privadas de crédito para descanso de mercaderes y particulares, y sin embargo rechazaban la idea de crear erarios públicos, por pensar que la opinión no los aceptaria.

Gracias al mencionado libro de Echevarria sobre Alberto Struzzi, he podido encontrar en la Biblioteca Nacional de Madrid un memorial de este consejero privado del Rey en el que expresa claramente tal dicotomía.

No se conoce con certeza la fecha de nacimiento de Struzzi (¿1560?-1638). Se le sabe parmesano, servidor del famoso general Alejandro Farnesio, Duque de Parma, en cuyo séquito marchó a Flandes cuando Felipe II nombró al Duque generalisimo de los ejércitos españoles en los Paises Bajos. Interesa recordar que Luis Valle de la Cerda fue contador del mismo Farnesio. Luego, se establecio Struzai en Madrid como representante de los archiduques soberanos en Flandes, Isabel Clara Eugenia y Alberto.

los historiadores le conociamos por dos publicaciones. La primera, un curioso y bello opúsculo de 12 páginas, Imago militiae auspicits Ambrosii Spino- 
lae 22 , compuesto para acompañar un ejército de juguete que el archiduque Alberto e Isabel Clara Eugenia regalaron al futuro cardenal infante don Fernando, mientras que al futuro Felipe IV enviaron Sus Altezas Serenisimas al enano Soplillo, probablemente el inmortalizado por Velázquez con un amplio sombrero y un gran mastín. La segunda y famosa publicación era una defensa del libre-cambio, notable en esa época mercantilista, con titulo Dialogo sobre el comercio destos reinos de Castilla, otro opusculo de apenas 32 páginas, publicado en 1624 y reimpreso en 162523 .

Gracias a la indicación de Echevarria he podido consultar un volumen encuadernado de memoriales de Struzzi, de la colección de Infantado en la Biblioteca Nacional de Madrid. Ahi se encuentra un escrito sobre Erarios. Comienza asi:

\section{Señor}

Alberto Struçi dice hauer uisto la premactica qe en 11 del mes de Hebrero de este año de 1623 sepublico de horden de V.Md. sobre Capitulos diuerssos, de Reformaçion, en los quales manda que para la conseruacion y augmento destos sus Reyos. Se establesscan ynstituyan y funden, Errarios, y Montes de Pie. dad adonde se reciua, y se de dineros a çenso, y Por uia de socorro, con la leyes, hordenanzas, calidades y Privilegios qe Ampareçido combenir y estan acordadas - -

El memorial entiende los dos fines de la reforma:

Y considerando que el obgeto principal consiste en estos dos puntos: El v'no emproponer a V.M $M^{\mathrm{d}}$. medios suaues y executiuos para hallar subsidio de sus Vasallos para el Remedio de las necessidades Eny. Al Presente se halla - - lo otro para remediar a los Pobres y necessitadosde Estos Reynos, quitando las ussuras y moatras $=-$

Luego expresa la resistencia del pueblo castellano a las innovaciones:

que el Proponer arbitrios con ymbenciones nucbas y aparentes suelen Caussar yncombenientes Entre el Pueblo Enemigo de nuebas Leves, Lo que no puede

2. In pequeno tratado de 12 folios. pubticado en 1614 con grabados de Stephamus van Schoor: acompañado de una su raduccion españolia bajo el titulo Imagen de una melica y de un ejercto firme

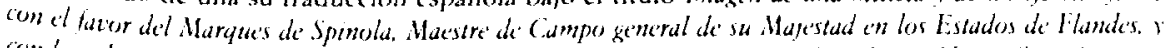

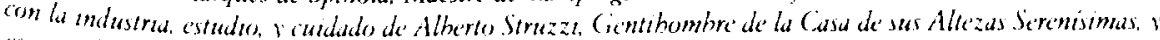

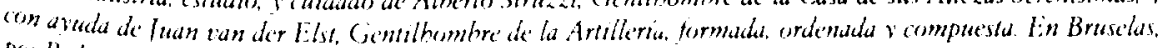

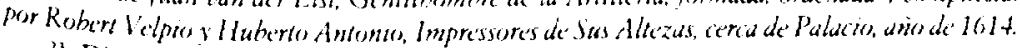

"Dice Echevarria que Struzai lo recscribio y amplio en 1629. en un manuscrito que no he visto y que se encuentra en Brusclas. Vichevarria (1995), p. 53. 
subceder Proponiendo essas que ayansido aprobadas y Executadas launque en páyses estrangeros) Como no sea mejorando de condicion ${ }^{24}$.

El escepticismo de Struzzi es aún mayor a la vista de la situación de desamparo económico de los castellanos.

Aunqe. Luys Valle de la çerda y el contador Sala Blanca en su libro disponen La forma de los Errarios, para el despempeño del Real Patrimonio con los montes de piedad dependientes dellos sea de considerar, si en aquellos tiempos en que el estado de las cosas Era muy diferrente de lo Presente, y las comodida. des mayores, no se Executaron...El caso es que mayores dificultades a deuer agora que Las comodidades que V. Magd. Y El Reyo. tienen son muy menores que solian ${ }^{25}$.

Pasa luego a distinguir entre los montes de piedad y los proyectados erarios, sobre la base de la confianza que pudiesen inspirar. Los montes

guardan el Credito Porque compuntualidad Pagan lo Principal quando se pide, y los ynteresses cada seys messes. Lo que sera dificultosso por Errarios sobre los quales el Principe tendra superioridad para servirse dellos lo que habra menester 20 .

Por esa razón no era posible unir erarios y montes de piedad bajo una sola administración.

$Y$ Enquanto a los montes de piedad que se preven seayan de fundar con el Dinero de los Errarios como dependientes dellos, tambien es cierto que no pueden ser unidos, sino del todo Separados, porque es materia muy diferente y Go. bierno muy diferente - - ademas que esta augmentacion y fundacion de los de flandes no es necesso. Que V.Maged. ni el Reyno hagan empleo particular de Dineros porque la persona que V.Magd. nombre por Superintendente General lo hallara como lo hallado Vincençio cobengue en Virtud del Priuilegio, y capitulos [que le fueron otorgados] ${ }^{27}$.

Visto todo ello, proponia Struzzi que, lejos de entregar la administración de los montes (que erarios no queria) a empleados de la Corona, se diese a factores privados.

24 "Erarios», Ms $10.441, \mathrm{BN}$, folio $234 \mathrm{r}$.

25 Folio 237 v.

23. Hechevarria (1995). pp. 197 a 202, citando del Archivo General de Simancas, Secretarias Provinciales, Jibro 1444, folio 96.

2: Folio $238 \mathrm{r}$. 
Por el papel del dho. Manuel Lopess perera se apunta que los 45 montes de Piedad sera combeniente darles por factoria a las Perssonas que los quissiessen tomar por su quenta dando fianzas, compago a los quales se les dara untanto por 100 de los reditos del dinero que empleassen ${ }^{28}$.

Si bien la idea de Struzzi no fue aplicada, sí interesó lo suficiente al monarca y a su ministro principal para que en 1625 se ordenara al factor del Monte de Piedad de Amberes, Wenceslas Cobergher, mencionado en el memorial de Struzzi, para que se trasladara a Madrid a fin de instalar «des Monts de Piété à l'exemple de...mes pays de par delà» ${ }^{24}$. Así es como se fundó el efímero Monte de Piedad de Madrid del año 1625. Nota Echevarria que hubo que esperar al año de 1702 para que se fundara en la Corte el definitivo, antecesor del hoy subsistente en Madrid.

\section{REFLEJOS INSTITUCIONALES}

La batalla de los erarios ilumina dos elementos de la historia institucional de Castilla. El primero es que la resistencia a las pretensiones del poder real no era de pacotilla; el segundo, que la obsesión de crear un banco nacional pervivió hasta ser plasmada en la realidad, pero pasado siglo y medio.

\section{Nueva visión de las Cortes}

Este relato de la mala fortuna del arbitrio de los erarios ilustra de manera muy viva la importancia y poder politico de las Cortes de Castilla durante los reinados de Felipe III y Felipe IV.

Ha sido el Dr. Thompson quien ha transformado nuestra vision del poder de las Cortes y de las ciudades con representación en ellas durante el siglo xvII. Lejos de ser las Cortes castellanas, y las aragonesas y catalanas, institituciones meramente ornamentales, en decadencia desde la derrota de los comuneros en Villalar en 1517, o desde la decapitación del Justicia Mayor de Aragón Lanuza en 1591, su poder de representación y resistencia se mantuvo e incluso se acrecentó: quizá fueran oligárquicas y reaccionarias, pero en todo caso frenaron el poder real, al menos hasta la victoria de los Borbones en la Guerra de Sucesión.

\footnotetext{
28 Folio $239 \mathrm{v}$.

24 Echevarria (1995), p. 202.
} 
La batalla de los erarios, como subraya Thompson, ilustra pues el poder de las ciudades con asiento en Cortes, como cabezas de partido que eran en la organización administrativa y económica de Castilla. Digo las ciudades, porque los procuradores eran a menudo sobornables por la Corona, pese a que hubiesen hecho "pleito omenage» $\mathrm{d}$ a no votar sino consultivamente en cuestiones que las ciudades consideraban cruciales. El propio Thompson hace ver como el cese de convocatorias de Cortes durante el reinado de Carlos II es indice, no de la debilidad de las Cortes como institución, pues la regente Mariana de Austria temia sus dilaciones, sino del poder superior y originario de las ciudades con las que la Corona paso a tratar directamente ". La anterior pervivencia de las Cortes desde 1600 hasta ese momento fue, según Thompson, una expresión cercana al «pactismo» que normalmente asociamos con la Corona de Aragon, en virtud del cual el rey aceptaba y ratificaba las disposiciones emanadas de las Cortes con la fórmula tradicional de

lo cual quiero que tenga fuerza de contrato mutuo, reciproco y obligatorio, hecho y otorgado entre partes ${ }^{31}$.

Si las Cortes dejaron de reunirse muerto Felipe IV fue porque costaban muy caras en prebendas para los procuradores y porque las ciudades encontraron más eficaz el entenderse directamente con la Corona sobre la concesión de «millones». Alcanzaron asi la victoria en su continuada resistencia a que aparecieran nuevas figuras impositivas permanentes, que la Corona había buscado para obviar la necesidad de aceptar en escritura formal los «memoriales de apuntamientos» asociados a la concesión de «millones».

De hecho, bajo Carlos II, gracias a la retirada de España como gran potencia en el concierto de las naciones europeas, la presión fiscal se aligeró y no volvieron a aprobarse nuevas figuras de impuesto. En medio del desastre general de la Monarquia y los Reinos Hispanos, las ciudades, con o sin sus Cortes, habian vencido. Pero, como dice Bennassar, con certera intuición, vencieron a costa del progreso constitucional:

En el siglo xu, Castilla habia avanzado de forma notable en la construccion del Estado moderno.... Pero la reacción de la nobleza, iniciada con Felipe II. confirmada en las épocas de Felipe IIl y Felipe IV, congeló la evolución, desgastó lentamente el aparato del poder $y$ sus mejores instrumentos y desvió las funciones de la monarquia tales como habian sido definidas por los Reyes Católi-

3) I. A. A. Thompson (1983), pp. 59-60.

"I. A. A. Thompson (1983), p. 19. 
cos, sin devolver a cambio la vida a las antiguas instituciones representativas o inventar unas nuevas ${ }^{32}$.

\section{El camino bacia un Banco Nacional}

La historia de los erarios en el pensamiento económico español no acaba aquí y se prolonga con las reverberaciones del arbitrio de los erarios hasta el establecimiento de un Banco Nacional.

Francisco Martinez de la Mata, reinando aún Felipe IV, hizo un fallido intento de resucitarlos en sus Memoriales y Discursos, según nos ha relatado detaIladamente D. Gonzalo Anes en su excelente edición de tales escritos. Entre 1650 y 1660 el motrileño De la Mata dio a conocer en Sevilla sus ideas para la restauración económica de España, en «papeles impresos» que publicaba y daba «a sus conocidos y con Carteles publicos que puso en la Plaza junto a las casas de Cabildo». Asi lo denunciaba un veinticuatro de Sevilla, quien temía que Mata desencadenara desórdenes públicos con su prédica, pues, vestido con el hábito de tercero de la Orden Franciscana, habia creado una Cofradia de Gremios y reunido discipulos para exigir la total prohibición de la entrada de mercaderías extranjeras, en especial los libros, y la sustitución de impuestos por los medios financieros que la Corona obtendria con la creación de erarios.

Las palabras son pausadas, las acciones de las manos repetidas, las admiraciones de los ojos como asombrados, y representando al Pueblo sus llagas de tributos y daños, con estos ademanes y exclamaciones predicables, podrian resultar los inconveniente que V.S. sabrá mejor conocer.

He aqui la viva representación de la persona denunciada por predicar, entre otras cosas, de nuestro arbitrio de los erarios ${ }^{33}$.

En el «Octavo Discurso» manifestaba nuestro predicador «de raiz la causa de haber menguado la Real Hacienda de Vuestra Magestad y la que ocasiona no poder salir de los empeños en que se halla, y se propone medio facil y suave de su restauracion», como rezaba el título. La razón de haber menguado la

12 Bartolomé Bennassar (1983), p. 56.

3t «D. Martin de Ulloa, veinticuatro de Sevilla, advierte los peligros que originaba Francisco Martinez de la Mata con sus memoriales y predicaciones», papel Ms. sellado en 1660 y conserva. do en la Real Academia de la Historia reproducido en: Memoriales y Discursos de Francisco Martinez de la Mata. Edición y nota preliminar de Gonzalo Anes (Madrid, 1971), Apéndice VIII, Pp. 483.92. 
prosperidiad era que se habia dado entrada a las mercaderías extranjeras; y el suave remedio consistía en la creación de erarios.

Reproduce Mata amplios pasajes de la Real Cédula o carta de Valsain de octubre de 1622, que he tenido ocasión de comentar más arriba, y que sin duda debió ser la dirigida al Ayuntamiento de Sevilla o al de Granada. Aduce Mata la «razón por la que los Erarios no se pudieron fundar»:

esta obra, de tan suma importancia, tengo por sin duda que se dejó de ejecutar por no hallarse medio suave y suficiente de formarles caudal.

Suspenso queda el lector en espera del modo de conseguir capital suficiente para esos establecimientos:

Y si Vuestra Magestad es servido de que se funden los Erarios en conformidad y modo que Vuestra Magestad lo tiene dispuesto y ordenado, yo me ofrezco a dar medio como tengan en tres años que se hayan fundado 12 millones ${ }^{34}$.

Caló el chapeo, fuése y no hubo nada.

Como relata Anes, Mata editó en 1659 Epitome de sus discursos, tres años después de haber publicado los textos in extenso. En 1701 se reeditó el tal Epitome y Campomanes, al considerarlo obra preciosa y rara, lo publicó en el Tomo I de su Apendice de la Educacion Popular (1775). Un lector mexicano de esta obra, un don Juan Eugenio de Santelices Pablo, envió a Campomanes «copia literal de los ocho discursos, sacada al pie de la letra de los impresos en folio, en veintiséis hojas» que se conservaban en una biblioteca particular de aquella ciudad. Asi pudo finalmente Campomanes reproducir esos discursos de Mata en el tomo IV del referido Apéndice ${ }^{35}$.

\section{Se prepara el Banco de San Carlos}

En el entretanto había aparecido espontaneamente en Castilla una institución financiera poderosa, la de los Cinco Gremios Mayores. Se habian unido en 1679 varias corporaciones de la Villa, para arrendar los tercios y alcabalas, y, llegado Felipe $\mathrm{V}$ al trono, empezaron a adelantar fondos a la Hacienda. En

34 Hubo una tercera edición en 1747 , por cierto dedicada a los ministros Carvajal y Lancaster.

"Campomanes, ibid, nota 277, p. 575. Véase el artículo subre el Sector financiero de P. Tedde de Lorca (1988), p. en el vol. I de la Enciclopedia de Historia de España, dirigida por Miguel Artola (Alianza Editorial, Madrid, 1988), p. 291 
1734, los Cinco Gremios Mayores reclamaron para sí esos arrendamientos y privilegios. En 1764, fundiéndose en una sola compañia, se convirtieron en un gran emporio de fabricación, transporte y banca pública y privada, de relaciones privilegiadas con la Hacienda. Estaban reunidos en esa compañia, sin embargo, poderosos hombres de negocios tradicionales y de ánimo monopolista, contrarios al grupo ilustrado. Por eso, Floridablanca, Campomanes y Cabarrús buscaron convencer al Rey Carlos III de que era necesario crear un Banco Nacional, en que centrar las relaciones financieras públicas y de suministro de pertrechos militares al Estado. España había entrado en otro periodo de actividad como gran potencia y la Corona necesitaba el apoyo de una institución financiera amiga de su politica de reformas ${ }^{36}$.

Campomanes anotó abundantemente todos los Discursos de Mata y en el Octavo dedicó largos comentarios al arbitrio de los erarios. No es al caso detenerme en ello, pero sí decir que el erudito y atento Fiscal entendió bien el porqué de la dificultad de fundar un «banco público» ${ }^{37}$ que era la falta de confianza en la primera mitad del siglo Xvil en establecimientos relacionados con la Corona.

Los bancos de Venecia y Génova corrian entonces y aún permanecen ahora, con el mayor crédito. Esta confianza pública no se establece tanto con reglamentos como por la buena administración de ambas repúblicas, que libran en ella su estabilidad y recurso en tiempos de urgencia.

Y Campomanes citaba a continuación los Cinco Gremios Mayores de Madrid, que,

por medio de su buena fe, y puntual cumplimiento, han adquirido la confianza de la nacion, sin más reglas que su conocimiento en el comercio, y un manejo diligente, para emplear bien los fondos que se les confian ${ }^{38}$.

Además, creía ver en el sistema de crarios un intento de crear crédito de la nada:

me parece un sistema semejante en el objeto al de Laws, en tiempo del Duque Regente ${ }^{34}$.

36. Vease Tedde de Lorca (1988), p. 291

1: Ibid., nota 277 , p. 575 .

"Martíne de la Mata, Ibid. «Discurso Octavom, pp. 246.7.

"39id, nota 277, p. 575. Martínez de la Mata, Lbid., "Discurso Octavo", pp. 246.7 
Nota Campomanes que «el retener la quinta parte de la renta, durante cinco años» era la forma de capitalización de los erarios propuesta por la Real Cédula y que «siempre un método semejante contenia alguna violencia»; pero la excusaba por «la gran decadencia causada en los dos anteriores reinados, cuyas resultas descargaron en el de Felipe IV».

Cuando, pese a las objeciones de Jovellanos y las acerbas criticas del marqués de Mirabeau, el gobierno de Carlos III decidió por iniciativa de Cabarrús lanzar un Banco Nacional bajo el nombre de Banco de San Carlos, el sueño del Conde Duque de alguna forma se cumplió. Pero ni durante los primeros años de su existencia el Banco no se mantuvo dentro de la ortodoxia financiera; $y$, removido Cabarrús reinando Carlos IV, fueron las necesidades de fondos que plantearon las guerras contra la República vecina, contra Portugal y luego contra Inglaterra las que dieron al traste con el invento, que murió rematado por la francesada ${ }^{\text {t1). }}$.

\section{FUENTES DE LA ÉPOCA}

Arcinvo General de Simancis: Contestaciones de las ciudades a la Cédula del Rey Fe. lipe IV desde Valsain en octubre de 1622, en la Sección Patronato Real, Caja 21.

Azpilcutia, M. DF: Doctor Navarro: Comentario resolutorio de usuras, Salamanca, 1557, edición del CSIC' (Madrid, 1965).

Biblioteca del. Monastierio de. San Lorfanzo del Escorial: Colección del Conde Duque de Olivares.

Chullos, Geronimo de: ARTE REAL / PARA EL BUEN GOVIERNO / de los Reyes, Principes, $y$ de sus Vasallos. En el / qual se refieren las obligaciones de cada uno, con los prin- / cipales documentos para el buen gouierno; / CON VNA TABLA DE I.AS MA- / terias, reducida a trezientos Aforismos de Latin y Romance. / Dirigido a la Catolica Magestad / del Rey don Felipe IV. N.S. Monarca y Emperador de Las / Españas, no reconociente superior en lo temporal. / LEGE ET REGE, /POR EL LICENCIADO GERONYMO DE ZEVA / llos, Regidor de la Imperial ciudad de Toledo en el rango, y asiento de / los Cavalleros, y vnico Patron del Monasterio de los Descalços / Franciscanos de la dicha ciudad. / Año M.DC XXIII. / En Toledo, A costa de su autor.

Contes de Castulla: Actas de las, editadas por la Real Academia de la Historia.

Campomanes, P. Rodrigulzz de: Apendice a la cducacion popular. Parte quarta, que contienen los exbo discursos de Francisco Martinez de Mala... (Madrid, 1777).

[EL REY]: Cèdula fechada en Valsain, el 29 de octubre de 1622, y dirigida "Al Concejo. Justicia, Regidores, Caualleros, escuderos y oficiales y hombres buenos de la muy noble ciudad de Valladolid", en: Archivo Histórico Español: La Junta de Reformación. Documentos... iranscritos por D. Angel Gonzallez Palencia, 1618-1625 (Valladolid. 1932).

411 Tedde de Lorca (1988), pp. 294.297. 
Martinez de la Mata, F.: Memoriales y Discursos de Francisco Martínez de la Mata. [1656] Edición y Nota Preliminar de Gonzalo Anes (Madrid, 1971).

MERCADO, T.: TRATOS Y CONTRATOS DE MERCADERES y tratantes discididos y deter. minados, por el Padre Presentado Fray Tomás de Mercado, de la Orden de los Predicadores. Con licencia y privilegio real. EN SALAMANCA. Por Mathias Gast. Año de 1569. Esta tassado en cinco reales. La segunda edición, de 1571, se tituló: SUMMA DE,/ TRA. TOS, Y CON-/TRATOS, COMPUESTA POR/ el muv Reuerendo Padre Fray Thomas de Mercado/ de la Orden de los Predicadores, Maestro en/ sancta Theologia. Diuidida en/ seys libros./ ANADIDAS A LA PRIMERA/ addicion, muchas nueuas soluciones. Y dos libros/ enteros, como paresce en la pagina siguiente/ [Una imagen de Sto. Domingo / Con licencia, y Priuilegio Real. / EN SEVILLA. / En casa de Hernando Diaz Impressor de Libros, / en la calle de la Sierpe. / 1571. La edición moderna que empleamos es la reedición de la segunda: Suma de Tratos y Contratos, edición de Nicolás Sánchez-Albornoz (Madrid, 1977).

Struzzl, A.: Imagen de una milicia y de un ejercito firme con el favor del Marques de Spinola, Maestre de Campo general de su Majestad en los Estados de Flandes, y con la industria, estudio, y cuidado de Alberto Struzzi, Gentibombre de la Casa de sus Altezas Serenísimas, y con ayuda de Juan van der Elst, Gentilbombre de la Artilleria, formada, ordenada y compuesta. En Bruselas, por Robert Velpio y Huberto Antonio, Impressores de Sus Altezas, cerca de Palacio, año de 1614.

- Memoriales de Struzzi en la colección de Infantado de la Biblioteca Nacional de Madrid: Erarios, MS 10.441.

ULLOA, M.: «D. Martin de Ulloa, veinticuatro de Sevilla, advierte los peligros que originaba Francisco Martinez de la Mata con sus memoriales y predicaciones", papel Ms. sellado en 1660 y conservado en la Real Academia de la Historia reproducido en: Memoriales y Discursos de Francisco Martínez de la Mata. Edición y nota preliminar de Gonzalo Anes (Madrid, 1971), Apéndice VIII, págs. 483.92.

VALIE DE IA CFRDA, L.: DESEMPEÑO/DEL PATRIMONIO DE / Su Magestad y de los Reynos, sin daño del Rey / y vasallos, y con descanso y/alivio de todos. / POR MEDIO DE LOS ERARIOS / públicos y Montes de Piedad / POR LUYS VALLE DE LACERDA / Del Consejo, y Contador de su Magestad/de la Santa Cruzada EN MADRID / En casa de Pedro Madrigal, / Año MDC.

\section{BIBLIOGRAFÍA}

Al.onso Rodriguez, B., y Garcta Garcia, A. (1993): «El pensamiento económico y el mundo del Derecho hasta el siglo xvim, ponencia inédita, presentada en el Congreso sobre «El pensamiento económico de la Escuela de Salamanca», 12.13 de noviembre de 1993 (Fundación Duques de Soria).

Barrientos Garcia, José (1985): Un siglo de moral económica en Salamanca (1526-1629). I. Francisco de Vitoria y Domingo de Soto, Salamanca.

BenNassar, B. (1983): La España del Siglo de Oro, Barcelona.

B.AUG, M. (1962): Pensamiento económico en retrospección Madrid. 
- (1992): «On the Historiography of Economics», ponencia presentada en el «Encuentro Ibérico sobre Historia del Pensamiento Económico», que tuvo lugar en Lisboa del 27 al 29 de abril.

Carrera Pujal., J. (1943-45): Historia de la economía española, vol. Il, Barcelona.

Diaz de: Diaz-Fernandez, J., y Estape, F. (1956): “La creación de Erarios públicos en España: el proyecto de Pedro de Oudegherste. Notas para la historia de la Banca en España», Moneda y Crédito, 56, pp. 41-53.

Echevarria Bacicialupe, M. A. (1995): Alberto Struzzi, un precursor del capitalismo liberal, Leuwen.

Elliotr, J. H. (1990): El Conde-Duque de Olivares: el politico de una época de decadencia, Barcelona.

El.liotT, J. H., y Pens, J. F. de la (1978): Memoriales del Conde Duque de Olivares, Madrid.

Ruiz Martin, F. (1969): «Los planes frustrados para crear una Red de Erarios y Montes de Piedad», Cuadenos Hispano-Americanos, pp. 238-240 (octubre-diciembre), pp. 607-644.

- (1970): «La banca en España hasta 1782», en El Banco de España, una bistoria económica, Madrid, pp. 64 a 96.

Sagredo, F. (1975): Proyecto de un Monte de Piedad en Burgos (1599), Boletín de Documentación del Fondo para la Investigación Económica y Social VIII (1975).

Stradling, R. A. (1989): Felipe IV y el gobierno de España, 1521-1665, Madrid.

TEDDF. DE. Lorca, P. (1988): El sector financiero, en el vol. I de la Enciclopedia de Historia de España, dirigida por Miguel Artola, Madrid.

Thompson, I. A. A. (1983): «La Corona y las Cortes de Castilla, 1590-1665», Revista de las Cortes Generales (1983), traducción del articulo del mismo autor «Crown and Cortes in Castile, 1590-1665», Estates and Representation, 2 (1982). 